\title{
Response to Comment on "Revised paleoaltimetry data show low Tibetan Plateau elevation during the Eocene"
}

\author{
Svetlana Botsyun ${ }^{1,2 *}$, Pierre Sepulchre' ${ }^{1}$ Yannick Donnadieu ${ }^{1,3}$, Camille Risi $^{4}$, Alexis Licht ${ }^{5}$, \\ Jeremy K. Caves Rugenstein ${ }^{6}$
}

${ }^{1}$ Laboratoire des Sciences du Climat et de l'Environnement, LSCE/IPSL, CEA-CNRS-UVSQ, Université Paris-Saclay, Gif-sur-Yvette, France. ${ }^{2}$ Department of Geosciences, University of Tübingen, Tübingen, Germany. ${ }^{3}$ Aix-Marseille Université, CNRS, IRD, Collège de France, CEREGE, Aix-en-Provence, France. ${ }^{4}$ Laboratoire de Météorologie Dynamique, IPSL, UPMC, CNRS, Paris, France. ${ }^{5}$ Department of Earth and Space Sciences, University of Washington, Seattle, WA, USA. ${ }^{6}$ Max Planck Institute for Meteorology, Hamburg, Germany.

${ }^{*}$ Corresponding author. Email: svetlana.botsyun@uni-tuebingen.de

Valdes et al. contest our results, suggesting failings in our modeling approach as well as in our comparison with data. Although their comment points to interesting ideas of improvement, we find that their critique reflects an incomplete understanding of our methods and is not supported by the material they provide.

Valdes et al. (1) argue that our modeling strategy (2) is incomplete, given that we ran an "atmosphere-only climate model with no feedbacks between the atmosphere, vegetation, and ocean." Two major drawbacks that Valdes et al. infer from this statement are that (i) we may capture an incomplete response of the climate system in terms of sea surface temperatures (SSTs) that could alter the hydrological cycle, and (ii) we miss potentially strong horizontal variations of $\delta^{18} \mathrm{O}$ in surface waters, ultimately leading to misestimations of rainfall $\delta^{18} \mathrm{O}$ over land.

The statement regarding the coupling is not rigorously correct. For our study (2), we ran the FOAM fully coupled model and the vegetation model LPJ forced by an Eocene paleogeography and greenhouse gas concentrations, specifically to capture the first-order response of SSTs and land surface in a coupled (but lower-resolution and not isotopeenabled) framework and incorporate their feedbacks when forcing LMDZiso with these boundary conditions. We argue that this is a major improvement compared to previous studies that have addressed paleo-elevations using isotopeenabled models [e.g., (3)].

Valdes et al. infer that changes in monsoon strength in our simulations would change the amount of upwelling and associated SSTs. We are aware that changes in topography can affect the upwellings system and SSTs (4), and for Quaternary paleoclimates, the record indeed suggests variations in upwelling in the Arabian Sea. But their amplitude and mechanistic link with monsoon activity is far from wellconstrained even for the present day (5). Also, Eocene upwellings in the Indian Ocean with a different paleogeography remain hypothetical. To our knowledge, no record of upwelling exists in the Asian region for the Eocene. Simulating realistic upwelling requires strong constraints on the regional bathymetry and models with far higher resolution than the isotope-enabled coupled models available, including HadCM3L.

Valdes et $a l$. are correct when they state that we do not simulate the horizontal response of $\delta^{18} \mathrm{O}$ in surface seawater. However, the consequences of these variations on the precipitation isotopic signature over the continent are an open question because air masses are subject to many fractionation processes after evaporation. Valdes et al.'s statement regarding Eocene "stronger horizontal gradients in stable isotopes (6), which may have an impact on the isotopic value of precipitation" is unsupported. Tindall et al. (6) do not show any stronger horizontal gradients in $\delta^{18} \mathrm{O}$ over the Eocene Indian Ocean when compared to the present. Their figure 4 shows that open Indian and Pacific oceans range between $-0.2 \%$ and $+0.2 \%$, with localized coastal values down to $-2 \%$, simulated on the western boundary of the Pacific, compared with higher values of $+0.5 \%$ o to $+2 \%$ o in the Paratethys sea. A similar west-east gradient was simulated in their present-day experiment when comparing depleted values simulated in the Gulf of Bengal with higher values in the Arabian basin. How large any putative horizontal gradients were in the Eocene, and how they would alter the rainfall isotopic signal, remain open questions that would need to be explored through an extensive set of both coupled and uncoupled simulations, which remains beyond the scope of our paper. We also note that these sea surface $\delta^{18} \mathrm{O}$ differences are dwarfed by the atmospheric fractionations simulated in our model. 
Valdes et al. also state that our simulated SSTs are "generally higher than data suggest (figure S12) and higher than we predict for the mid-Eocene." We dispute this statement. Our figures S1 and S12 (2) show that simulated SSTs are in the very same ranges as the ones simulated in the HadCM3L Eocene experiment by Tindall et al. (6) (compare with their figures 1 and 3), i.e., ranging from $22^{\circ}$ to $26^{\circ} \mathrm{C}$ in the Paratethys sea and from $30^{\circ}$ to $36^{\circ} \mathrm{C}$ in the Indian Ocean.

For comparison with our results, Valdes et al. (1) provide a simulation exercise that is not easy to evaluate in the absence of proper model-data evaluation and detailed outputs. Specifically, they only provide interpolated isotopic fields with no information about atmospheric dynamics or rainfall amount. Further, their simulation rainfall $\delta^{18} \mathrm{O}$ is not necessarily consistent with Rayleigh distillation. Some (seemingly three) of their highest $(>4000 \mathrm{~m})$ elevation points indeed provide low $\delta^{18} \mathrm{O}$ values ( -8 to $-9 \%$, given the color bar provided), but others (especially the central and western part of their plateau) are less depleted than the lower eastern Asian continent, precluding any conclusion regarding the lapse rate. Interestingly, their outputs have some similarities with ours, with depletion occurring at low surface elevations between $90^{\circ}$ and $110^{\circ} \mathrm{E}$ that we infer could be linked to the same processes we described.

We stress that in our study (2), we made the choice to use high spatial resolution at the expense of using a full lower-resolution coupling of the isotopes in the atmosphere and the ocean, given that previous studies $(7,8)$ had shown that high-resolution simulations are required to capture the observed spatial, seasonal, and daily variations of precipitation $\delta^{18} \mathrm{O}$ over the Tibetan Plateau. In particular, the zoomed simulation with LMDZiso shows a marked improvement relative to the coarse simulation with the same model. Likewise, the low spatial resolution of Valdes et al. likely does not allow explicit simulation of air masses as they ascend over the edge of the Tibetan Plateau.

Valdes et al. also challenge the credibility of LMDZiso simulations based on two alleged model shortcomings. We find that both of these arguments do not hold upon closer inspection. However, we acknowledge that our findings would benefit from an intercomparison initiative that would allow better quantification of uncertainties among isotopeenabled models applied to past climates.

The first shortcoming is that LMDZiso fails "to represent the isotopic depletion measured in Quaternary tropical ice cores." We assume that this comment refers to the underestimated depletion observed in high-altitude tropical ice cores during the Last Glacial Maximum (LGM). This problem is common to almost all general circulation model (GCM) simulations that have been published [e.g., (9)]. However, this underestimated LGM depletion is probably caused by a resolution that is too coarse. For example, in the only high-resolution isotopic simulation of the LGM that has been published to our knowledge (10), which was with LMDZiso, the very depleted values observed in Tibetan ice cores are well captured (see their figure S12). The finer the resolution, the more depleted the precipitation is at tropical ice core locations. Therefore, the zoomed LMDZiso simulation used in our study is probably more reliable for simulating the processes that lead to isotopic variations in highlatitude tropical regions than any other GCM simulation with coarse resolution.

The second shortcoming noted by Valdes et al. is the failure of LMDZiso to simulate the $\delta^{18} \mathrm{O}$-altitude relationship over the Tibetan Plateau region. However, they cite a paper by Gao et al. (8) in which the zoomed simulation with LMDZiso was compared with only five stations in the Himalayan-Tibetan region. These five stations represent a very small sample of stations, and the observed isotopic lapse rate among these five stations is not even monotonic, confirming that this is too small a sample to reach any reliable conclusion. Furthermore, all of these five sites fall in LMDZiso grid boxes that are either below $2000 \mathrm{~m}$ or above $4000 \mathrm{~m}$. This huge altitudinal gap precludes any reliable comparison between observed and simulated lapse rate and makes this comparison even less reliable. A much more reliable comparison of observed and modeled isotopic lapse rate can be found in (7). There, model simulations are compared to 35 stations in the Tibetan Plateau region, including 24 stations from the GNIP and TNIP networks and 11 ice cores. In their section 5.2, the observed and modeled isotopic lapse rates were compared for different seasons and different regions. The article concludes that the zoomed simulation with LMDZiso captures the isotopic lapse rate very well. For example, in annual average, in the Westerlies domain, the isotopic lapse rates are $-0.17 \%$ o $(100 \mathrm{~m})^{-1}$ and $-0.16 \%$ o $(100 \mathrm{~m})^{-1}$ in observations and zoomed LMDZiso, respectively. In the monsoon domain, the isotopic lapse rates are $-0.13 \%$ o $(100 \mathrm{~m})^{-1}$ and $-0.88 \%$ o $(100 \mathrm{~m})^{-1}$ in observations and zoomed LMDZiso, respectively. The article concludes that LMDZiso rather overestimates the isotopic lapse rate. Overall, the zoomed simulation with LMDZiso shows the best agreement with observations among the different models used in this study.

Both (7) and (8) compare observations with models of different resolutions. Both papers conclude that over the Tibetan Plateau, a high-resolution model is necessary to capture the spatial, seasonal, and daily variations of precipitation $\delta^{18} \mathrm{O}$ that are observed. In particular, the zoomed simulation with LMDZiso shows a marked improvement compared to the coarse simulation with the same model. Therefore, we argue that more confidence can be ascribed to the zoomed simulation with LMDZiso than to coarseresolution simulations. 
In contrast to what Valdes and others declare, we do not claim that the altitude was the only driver of $\delta^{18} \mathrm{O}$ signal. On the contrary, we explicitly showed that simulated $\delta^{18} \mathrm{O}$ distribution over Asia follows changes (i) in the hydrological cycle in hotter Eocene environment due to higher $\mathrm{CO}_{2}$, and (ii) in moisture pathways due to the paleogeographical changes. The isotopic lapse rate simulated by a GCM is expected to be sensitive to the representation of convective processes, cloud processes (which underlie the orographic precipitation), continental recycling, and more generally all physical processes that feed back on the large-scale circulation, including cloud processes (11).

Regarding our model-data strategy, we stress that a common practice in deeptime paleoclimate modeling is to choose a time period and assume that data that are both older and younger than the "target" time period can be used in the data-model comparison. This practice recognizes the uncertainties in paleogeographic and paleoclimatic reconstructions, such that a precise reconstruction of 40 Ma likely encompasses paleogeographies and climates that overlap several million years before and after the "target" time period. We note that precipitation $\delta^{18} \mathrm{O}$ values across Asia show very little change over the past $50 \mathrm{Ma}$ (12). Data from central Asia have values that range from -12 to $-8 \%$ o throughout the entirety of the Cenozoic, and these values are enriched relative to data from the Tibetan Plateau, which is nearly always lower than $-15 \%$. This lack of abrupt changes in calcite $\delta^{18} \mathrm{O}$ through time indicates that it is not critical to use data from precisely the same time period as our "target" time period.

We stress that the Eocene paleogeography is far from being universally accepted, and we provided multiple sensitivity tests to capture this uncertainty. Nevertheless, our primary scenario is firmly within the paleomagnetic constraints provided by Huang et al. (13). Additionally, the existence of complex topography in Tibet remains largely untested, and evidence for such complexity remains circumstantial at best (14). Such topographic complexity might not even translate to a corresponding effect on precipitation $\delta^{18} \mathrm{O}$. For example, the North American Cordillera displays enormous topographic complexity between the Sierra Nevada and the Rockies; however, there is very little change in precipitation $\delta^{18} \mathrm{O}$ across this complexity (15). In contrast, Tibet has relatively little topographic complexity, yet there is a $10 \%$ change in precipitation $\delta^{18} \mathrm{O}$ across the Plateau (12).

We acknowledge that depending on the type of sample from which precipitation $\delta^{18} \mathrm{O}$ is reconstructed, we might expect different uncertainties. However, to date no one has been able to demonstrate that modern-day lacustrine carbonates record topographic complexity. Given this uncer- tainty in the modern, any assumptions about the expected data structure, in an attempt to better represent the uncertainties, will be difficult or impossible to verify, thereby lending neither additional constraints on the uncertainty nor more accurate estimates of the topographic complexity. Additionally, we already use the lowest $\delta^{18} \mathrm{O}$ from lacustrine systems (and provide a test where we only use the lowest $\delta^{18} \mathrm{O}$ from pedogenic carbonates). This data treatment already assumes that we are only capturing potential highelevation, non-evaporatively enriched data (in this framework), and yet we still find that a lower topography is a better fit. Thus, we conclude that our statistical test permits us to avoid unjustified assumptions on the data structure.

To conclude, we confirm the robustness of our approach, while welcoming further model-data comparison studies that combine multiple proxy types (alkane $\delta \mathrm{D}$, leaves, etc.), together with additional modeling efforts testing the impact of complex topography structures as well as atmospheric physics parameterizations on $\delta^{18} \mathrm{O}$. Such multiproxy, multimodel efforts will go a long way toward testing the hypotheses we have put forward in our study of Eocene climate over Tibet.

\section{REFERENCES}

1. P. J. Valdes, D. Lin, A. Farnsworth, R. A. Spicer, S.-H. Li, S. Tao, Comment on "Revised paleoaltimetry data show low Tibetan Plateau elevation during the Eocene". Science 365, eaax8474 (2019).

2. S. Botsyun, P. Sepulchre, Y. Donnadieu, C. Risi, A. Licht, J. K. Caves Rugenstein, Revised paleoaltimetry data show low Tibetan Plateau elevation during the Eocene. Science 363, eaaq1436 (2019). doi:10.1126/science.aaq1436

3. C. J. Poulsen, T. A. Ehlers, N. Insel, Onset of convective rainfall during gradual late Miocene rise of the central Andes. Science 328, 490-493 (2010). doi:10.1126/science. 1185078 Medline

4. P. Sepulchre, L. C. Sloan, M. Snyder, J. Fiechter, Impacts of Andean uplift on the Humboldt Current system: A climate model sensitivity study. Paleoceanography 24, PA4215 (2009). doi:10.1029/2008PA001668

5. M. Balaji, A. Chakraborty, M. Mandal, Changes in tropical cyclone activity in north Indian Ocean during satellite era (1981-2014). Int. J. Climatol. 38, 2819-2837 (2018). doi:10.1002/joc.5463

6. J. Tindall, R. Flecker, P. Valdes, D. N. Schmidt, P. Markwick, J. Harris, Modelling the oxygen isotope distribution of ancient seawater using a coupled oceanatmosphere GCM: Implications for reconstructing early Eocene climate. Earth Planet. Sci. Lett. 292, 265-273 (2010). doi:10.1016/j.epsl.2009.12.049

7. T. Yao, V. Masson-Delmotte, J. Gao, W. Yu, X. Yang, C. Risi, C. Sturm, M. Werner, H. Zhao, Y. He, W. Ren, L. Tian, C. Shi, S. Hou, A review of climatic controls on $\delta^{18} \mathrm{O}$ in precipitation over the Tibetan Plateau: Observations and simulations. Rev. Geophys. 51, 525-548 (2013). doi:10.1002/rog.20023

8. J. Gao, V. Masson-Delmotte, T. Yao, L. Tian, C. Risi, G. Hoffmann, Precipitation water stable isotopes in the south Tibetan Plateau: Observations and modeling. J. Clim. 24, 3161-3178 (2011). doi:10.1175/2010JCLI3736.1

9. S. Jasechko, A. Lechler, F. S. R. Pausata, P. J. Fawcett, T. Gleeson, D. I. Cendón, J. Galewsky, A. N. LeGrande, C. Risi, Z. D. Sharp, J. M. Welker, M. Werner, K. Yoshimura, Late-glacial to late-Holocene shifts in global precipitation $\delta^{18} \mathrm{O}$. Clim. Past 11, 1375-1393 (2015). doi:10.5194/cp-11-1375-2015

10. R. A. Eagle, C. Risi, J. L. Mitchell, J. M. Eiler, U. Seibt, J. D. Neelin, G. Li, A. K. 
Tripati, High regional climate sensitivity over continental China constrained by glacial-recent changes in temperature and the hydrological cycle. Proc. Natl. Acad. Sci. U.S.A. 110, 8813-8818 (2013). doi:10.1073/pnas.1213366110 Medline

11. B. Stevens, S. Bony, What are climate models missing? Science 340, 1053-1054 (2013). doi:10.1126/science.1237554 Medline

12. J. K. Caves Rugenstein, C. P. Chamberlain, The evolution of hydroclimate in Asia over the Cenozoic: A stable-isotope perspective. Earth Sci. Rev. 185, 1129-1156 (2018). doi:10.1016/j.earscirev.2018.09.003

13. W. Huang, G. Dupont-Nivet, P. C. Lippert, D. J. J. van Hinsbergen, M. J. Dekkers, R. Waldrip, M. Ganerød, X. Li, Z. Guo, P. Kapp, What was the Paleogene latitude of the Lhasa terrane? A reassessment of the geochronology and paleomagnetism of Linzizong volcanic rocks (Linzhou basin, Tibet). Tectonics 34, 594-622 (2015). doi:10.1002/2014TC003787

14. P. G. DeCelles, I. S. Castañeda, B. Carrapa, J. Liu, J. Quade, R. Leary, L. Zhang, Oligocene-Miocene Great Lakes in the India-Asia Collision Zone. Basin Res. 30, 228-247 (2018). doi:10.1111/bre.12217

15. G. J. Bowen, C. D. Kennedy, Z. Liu, J. Stalker, Water balance model for mean annual hydrogen and oxygen isotope distributions in surface waters of the contiguous United States. J. Geophys. Res. Biogeosci. 116, G04011 (2011). doi:10.1029/2010JG001581

\section{ACKNOWLEDGMENTS}

Funding: This work was funded by the FP7-PEOPLE: Marie-Curie Actions [grant 316966, iTECC (interaction Tectonics-Erosion-Climate-Coupling) project]. S.B. is supported by the German Ministry for Education and Research (BMBF) grant 03T0863A and German Science Foundation (DFG) grant EH329/19-1 to T. Ehlers. J.K.C.R. is funded by an Alexander von Humboldt Fellowship. Author contributions: All authors contributed to researching and writing this response.

24 May 2019; accepted 9 August 2019

Published online 20 September 2019

10.1126/science.aax8990 


\section{Science}

\section{Response to Comment on "Revised paleoaltimetry data show low Tibetan Plateau elevation during the Eocene"}

Svetlana Botsyun, Pierre Sepulchre, Yannick Donnadieu, Camille Risi, Alexis Licht and Jeremy K. Caves Rugenstein

Science 365 (6459), eaax8990.

DOI: $10.1126 /$ science.aax8990

ARTICLE TOOLS

REFERENCES

PERMISSIONS http://science.sciencemag.org/content/365/6459/eaax8990

This article cites 15 articles, 5 of which you can access for free http://science.sciencemag.org/content/365/6459/eaax8990\#BIBL

http://www.sciencemag.org/help/reprints-and-permissions 